\title{
Long Non-Coding RNA GAS5 and Intestinal MMP2 and MMP9 Expression: A Translational Study in Pediatric Patients with IBD
}

\author{
Marianna Lucafò ${ }^{1}{ }^{(}$, Letizia Pugnetti ${ }^{2}$, Matteo Bramuzzo ${ }^{1}$, Debora Curci ${ }^{2}$, \\ Alessia Di Silvestre ${ }^{2}$, Annalisa Marcuzzi ${ }^{1}{ }^{1}$, Alberta Bergamo ${ }^{3}$, Stefano Martelossi ${ }^{4}$, \\ Vincenzo Villanacci ${ }^{5}$, Anna Bozzola ${ }^{5}$, Moris Cadei ${ }^{5}$, Sara De Iudicibus ${ }^{1}$, Giuliana Decorti ${ }^{1,6, *}$ \\ and Gabriele Stocco ${ }^{7}$ \\ 1 Institute for Maternal and Child Health-IRCCS “Burlo Garofolo", 34137 Trieste, Italy; \\ marianna.lucafo@burlo.trieste.it (M.L.); matteo.bramuzzo@burlo.trieste.it (M.B.); \\ annalisa.marcuzzi@burlo.trieste.it (A.M.); sadeiu@libero.it (S.D.I.) \\ 2 PhD School in Science of Reproduction and Development, University of Trieste, 34127 Trieste, Italy; \\ letizia.pugnetti@libero.it (L.P.); dcurci@units.it (D.C.); alessia.disilvestre@gmail.com (A.D.S.) \\ 3 Callerio Foundation Onlus, 34127 Trieste, Italy; a.bergamo@callerio.org \\ 4 Cà Foncello Hospital, 31100 Treviso, Italy; stefano.martelossi@aulss2.veneto.it \\ 5 Pathology Section, Spedali Civili, 25123 Brescia, Italy; vincenzo.villanacci@asst-spedalicivili.it (V.V.); \\ anna.bozzola@gmail.com (A.B.); moriscadei@vodafone.it (M.C.) \\ 6 Department of Medicine, Surgery and Health Sciences, University of Trieste, 34127 Trieste, Italy \\ 7 Department of Life Sciences, University of Trieste, 34127 Trieste, Italy; stoccog@units.it \\ * Correspondence: decorti@units.it; Tel.: +39-04-0558-8634
}

Received: 24 September 2019; Accepted: 21 October 2019; Published: 24 October 2019

\begin{abstract}
Background: The long non-coding RNA (lncRNA) growth arrest-specific transcript 5 (GAS5) seems to be involved in the regulation of mediators of tissue injury, in particular matrix metalloproteinases (MMPs), implicated in the pathogenesis of inflammatory bowel disease (IBD). We investigated the role of GAS5 in regulating MMP2 and MMP9 expression in pediatric patients with IBD and in vitro. Methods: In total, 25 IBD patients were enrolled: For each patient paired inflamed and non-inflamed biopsies were collected. RNA was extracted and GAS5, MMP2, and MMP9 were quantified by TaqMan assay. The expression of GAS5 and MMPs was also determined in the human monocytic THP1 cells differentiated into macrophages and stimulated with lipopolysaccharide (LPS). The function of GAS5 was assessed by overexpressing the lncRNA and evaluating the MMPs levels. Results: Real-time PCR results demonstrated a downregulation of GAS5 and an upregulation of both MMPs in inflamed tissues. In vitro data confirmed the trend observed in patients for the three genes: The stimulation with LPS promoted a downregulation of GAS5 while an increase of MMPs was observed. Overexpression experiments showed that higher levels of GAS5 lead to a decrease of both enzymes. Conclusion: These results provide new information about the role of GAS5 in IBD: The lncRNA could mediate tissue damage by modulating the expression of MMPs.
\end{abstract}

Keywords: inflammatory bowel disease; long non-coding-RNA; GAS5; MMP2; MMP9

\section{Introduction}

Inflammatory bowel disease (IBD) includes two different pathologies, Crohn's disease (CD) and ulcerative colitis (UC), that, although different in their pathogenesis, show common clinical characteristics such as chronic inflammation at different levels of the gastrointestinal tract and a dysregulated excessive immune response [1]. Both CD and UC are characterized by chronic changes 
in the intestinal tissues, consisting of an intense infiltration of lymphocytes and plasma cells and deep remodeling of the connective tissue, leading to increased turnover of extracellular matrix (ECM) components [2]. Disturbance of the balance between the synthesis and degradation of ECM elements may result in progressive intestinal barrier destruction.

Degradation of ECM components is tightly controlled by the enzymatic activity of matrix metalloproteinases (MMPs), proteins that play an important role in the pathogenesis of IBD [3]. MMPs are secreted as pro-enzymes and require cleavage of the pro-peptide to become active. Increased levels of these proteins in the intestinal mucosa of IBD patients have been reported: The epithelial-derived $M M P 9$ is an important mediator of tissue injury in colitis, whereas MMP2 maintains gut barrier function, favoring infiltration processes of leukocytes in inflamed tissue [4-8].

Long non-coding RNAs (lncRNAs) have emerged as important gene expression regulatory elements and recent data have implicated the deregulated expression of certain lncRNA networks in the pathogenesis of autoimmune and inflammatory diseases, such as IBD [9-11]. In this context, one of the most studied IncRNAs is growth arrest-specific transcript 5 (GAS5). GAS5 can be deregulated by different pro-inflammatory stimuli in vitro [12-14]. Moreover, GAS5 attenuates the expression and the activity of MMP2 and MMP9 and has a role in regulating the metastasis phenotype of melanoma cells $[15,16]$; however, no data are published about the role of GAS5 as a regulator of MMP9 and MMP2 expression in IBD patients.

In the present study, our research focused on the potential role of GAS5 in regulating the transcription of $M M P 2$ and $M M P 9$, starting from their evaluation in inflamed and non-inflamed colonic tissues of pediatric patients with IBD. Moreover, considering that activated monocytes and macrophages are the major contributors of $M M P 9$ and $M M P 2$ in inflammatory diseases [17,18], an in vitro study on these cellular models was done to investigate the association between GAS5 and the two MMPs' expression.

\section{Results}

\subsection{Patients}

Twenty-five children with IBD (CD 13; UC 12) were enrolled at diagnosis in this study and their baseline characteristics and histologic findings are shown in Table 1.

Table 1. Characteristics and histologic scores of the patients.

\begin{tabular}{|c|c|}
\hline Patients ( $n$ ) & 25 \\
\hline Age (mean, range) & $12.5,6.2-18$ \\
\hline Male (\%) & $13(52 \%)$ \\
\hline $\mathrm{CD}(\%)$ & $13(52 \%)$ \\
\hline UC (\%) & $12(48 \%)$ \\
\hline $\begin{array}{c}\text { Clinical score: } \\
\text { PCDAI }^{1} \text { (mean, range) } \\
\text { PUCAI }^{2} \text { (mean, range) }\end{array}$ & $\begin{array}{c}30.6,7.5-55 \\
30.1,10-75\end{array}$ \\
\hline \multirow[t]{2}{*}{$\begin{array}{l}\text { Histologic findings: } \\
\text { Inflammation score }\end{array}$} & Score (\% of patients) \\
\hline & $\begin{array}{c}0(0 \%) \\
1(4 \%) \\
2(24 \%) \\
3(36 \%) \\
4(28 \%) \\
5(8 \%)\end{array}$ \\
\hline \multirow[t]{2}{*}{ Architectural score } & Score (\% of patients) \\
\hline & $\begin{array}{c}0(0 \%) \\
1(8 \%) \\
2(28 \%) \\
3(52 \%) \\
4(12 \%)\end{array}$ \\
\hline
\end{tabular}

${ }^{1}$ Pediatric Crohn's Disease Activity Index; ${ }^{2}$ Pediatric Ulcerative Colitis Activity Index. 


\subsection{GAS5 Expression in Mucosal Biopsies of Pediatric IBD Patients}

For each patient, during colonoscopy, an inflamed and a non-inflamed biopsy was collected in TRIzol reagent. GAS5 gene relative expression was evaluated, showing a statistically significant downregulation in inflamed mucosa in comparison to the non-inflamed one (Figure 1 and supplementary Table S1).

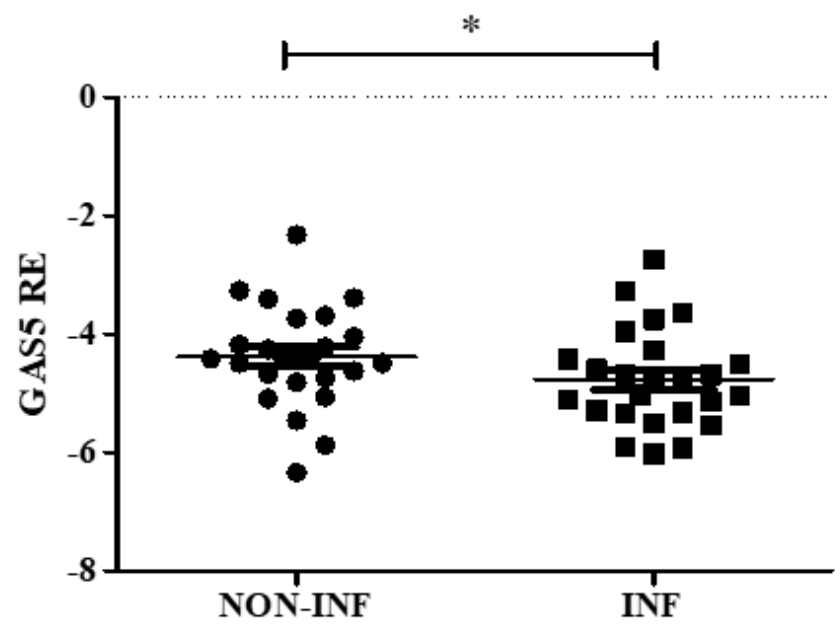

Figure 1. Growth arrest-specific transcript 5 (GAS5) levels in colon biopsies of inflammatory bowel disease (IBD) pediatric patients. Expression was evaluated in inflamed (INF) and non-inflamed (NON-INF) tissues for each patient. GAS5 expression was normalized using RPLP0 gene. Relative expression (RE) values are expressed as $\log _{2} 2^{-\Delta C t}$. Paired $t$ test ${ }^{*} p<0.05$.

\section{GAS5 Correlation with Disease Activity Scores}

Interestingly, GAS5 levels were negatively associated with the clinical scores reported in Table 1. No significant association was found with the inflammation and architectural parameters (Figure 2).

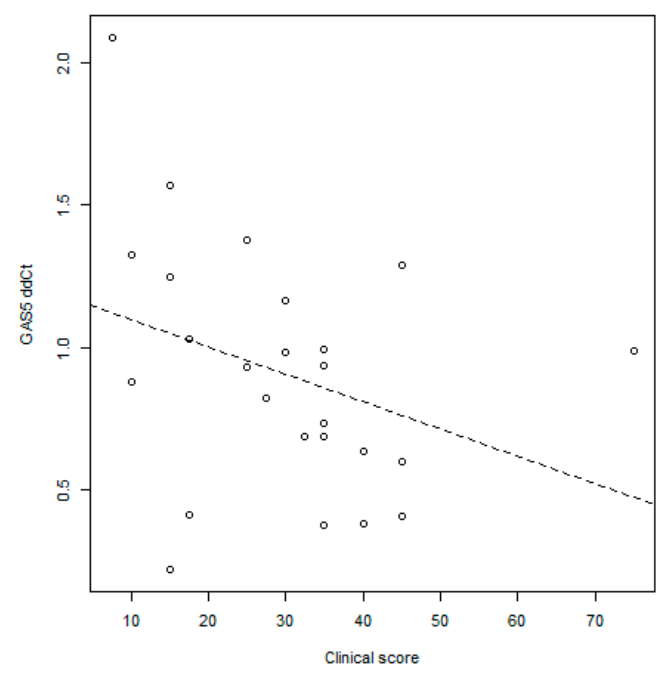

Figure 2. Correlation between GAS5 levels evaluated in inflamed tissue and the clinical score; Spearman test $p=0.048 ; r=-0.40$.

\subsection{MMP2 and MMP9 Gene and Protein Expression in Colon Biopsies of Pediatric IBD Patients}

Gene and protein expression analyses were performed to study the relation between the enzymes and GAS5 in colon biopsies of pediatric patients with IBD at diagnosis. Real-time PCR results demonstrated an increased expression of both MMPs in inflamed tissues (Figure 3 and supplementary Table S1). 

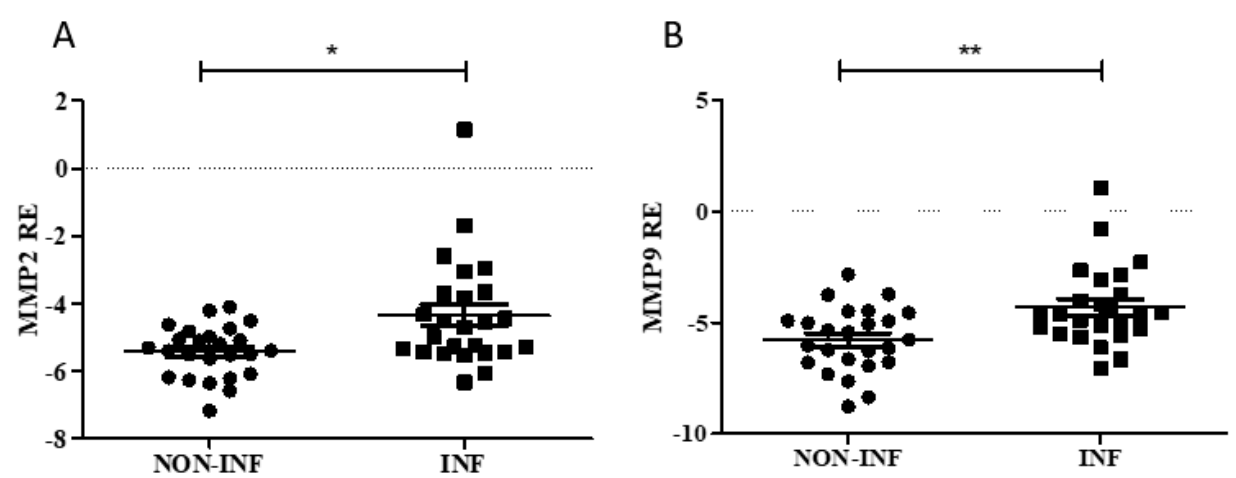

Figure 3. MMP (matrix metalloproteinase) levels in colon biopsies of IBD pediatric patients. MMP2 (A) and MMP9 (B) expression was evaluated in inflamed (INF) and non-inflamed (NON-INF) tissues for each patient and normalized using RPLPO gene. Relative expression (RE) values are expressed as $\log _{2}$ $2^{-\Delta \mathrm{Ct}}$. Paired $t$ test ${ }^{*} p<0.05,{ }^{* *} p<0.01$.

Immunoblotting analysis of the MMP9 and MMP2 proteins was also performed on inflamed and non-inflamed biopsies of three additional patients (mean age at enrolment 13.8 years, two UC and one $\mathrm{CD}$, two males and one female). An increase in the expression of both proteins in inflamed tissues compared to non-inflamed ones was observed (Figure 4).

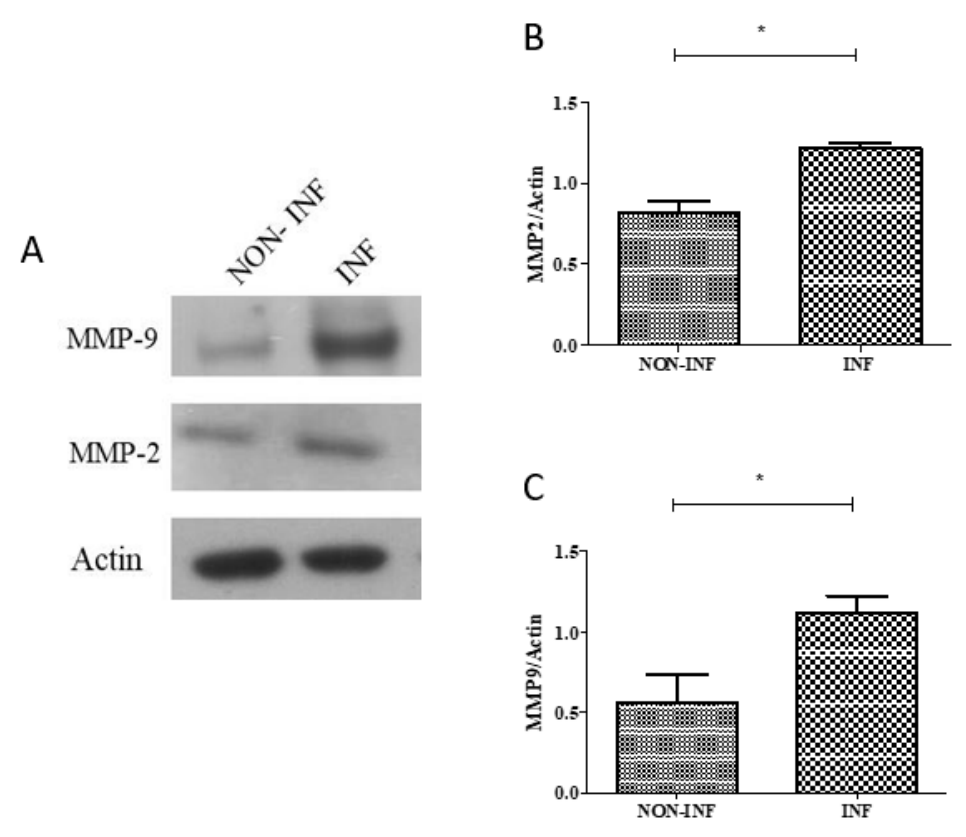

Figure 4. MMP2 (74 kDa; A and B) and MMP9 (92 kDa; A and C) protein expression in colon biopsies of IBD pediatric patients analyzed by immunoblotting. Protein lysates were obtained from inflamed (INF) and non-inflamed (NON-INF) tissues. Actin (42 kDa) was used as internal loading control. Representative western blot reflecting $M M P 2, M M P 9$ and actin protein levels. Paired $t$ test $* p<0.05$.

\subsection{GAS5, MMP2, and MMP9 Gene Expression in the THP1 Cell Line}

The THP1 human monocytic cell line was chosen as the cellular model to confirm the involvement of GAS5 in the regulation of MMP2 and MMP9 expression. Experiments were conducted at different stages of differentiation, from monocyte (THP1) to macrophages (THP1 + PMA (phorbol-12-myristate 13-acetate)). The effects of stimulation by LPS was also tested. Real-time PCR results of GAS5 expression showed a downregulation of its levels in stimulated cells compared to unstimulated THP1. A decrease of GAS5 was also evident in PMA-differentiated macrophages compared to monocytes, while LPS treatment did not further reduce GAS5 expression (Figure 5). 

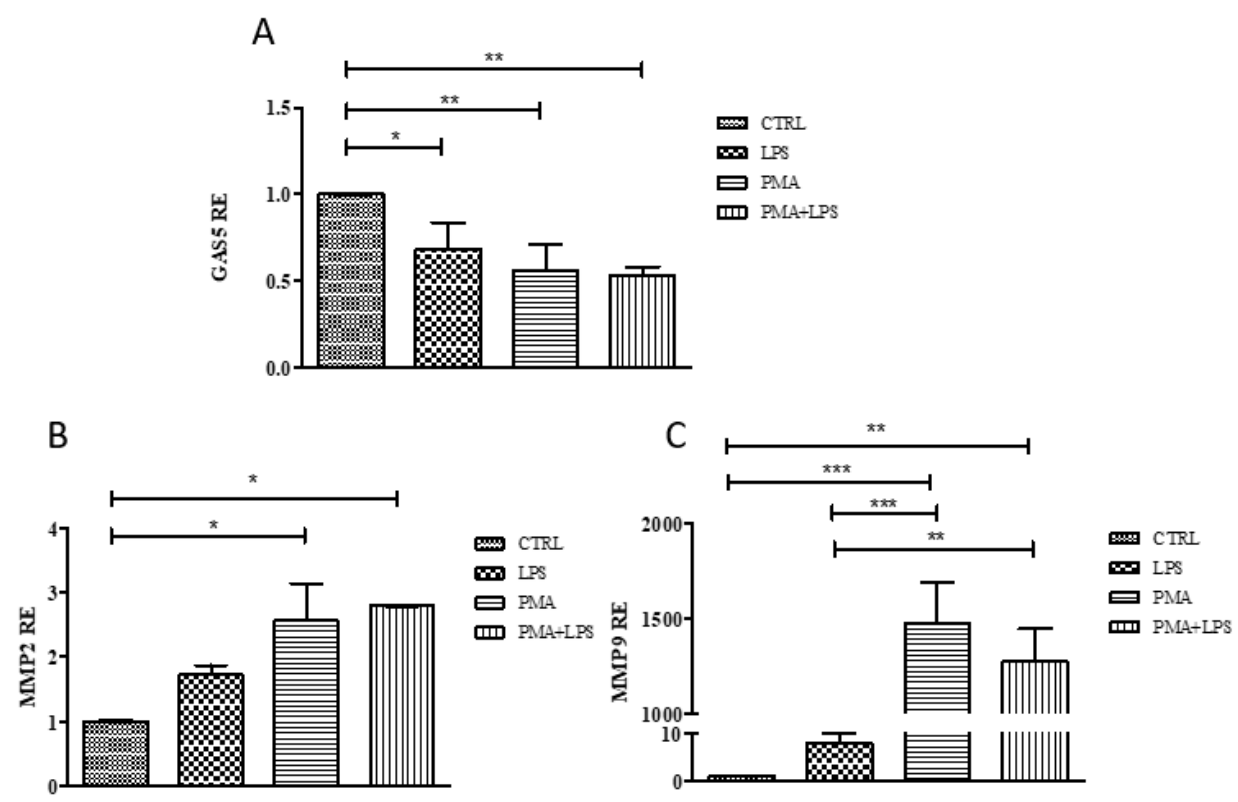

Figure 5. Relative expression (RE, values are expressed as $2^{-\Delta \mathrm{Ct}}$ ) of GAS5 (A), MMP2 (B), and MMP9 (C) in THP1 cells exposed to LPS (lipopolysaccharide), PMA (phorbol-12-myristate 13-acetate), and PMA + LPS. GAS5, MMP2, and MMP9 expression was normalized using $18 S$ gene. One-way ANOVA GAS5 $p=0.003$, MMP2 $p=0.018$, MMP9 $p<0.0001$ Bonferroni's multiple comparison post-test * $p<0.05$, ** $p<0.01,{ }^{* * *} p<0.001$.

MMP2 and MMP9 expression levels increased in stimulated cells, particularly in PMA-differentiated macrophages, with a similar trend for both MMPs (Figure 5), confirming the trend observed in patients.

\subsection{MMP2 and MMP9 Gene Expression in Cells Transfected with the pcDNA3.1-GAS5 Plasmid}

Following the transient transfection with pcDNA-GAS5 plasmid, the efficiency of the overexpression of the IncRNA on both monocyte (THP1) and macrophages (THP1 + PMA) was assessed by real-time PCR (Figure 6).

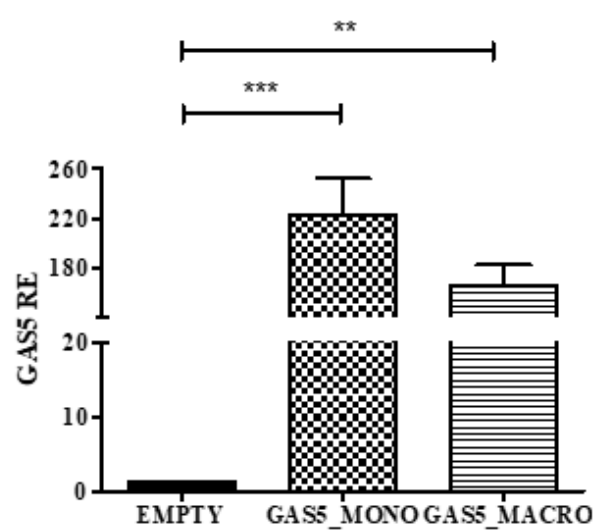

Figure 6. Evaluation of GAS5 levels after transfection with pcDNA-GAS5 plasmid in monocytes (GAS5_MONO) and macrophages (GAS5_MACRO). GAS5 expression was normalized using GAPDH gene and relative expression (RE) values are expressed as $2^{-\Delta \mathrm{Ct}}$. One-way ANOVA GAS5 $p=0.0005$, Bonferroni's multiple comparison post-test ${ }^{* *} p<0.01,{ }^{* * *} p<0.001$.

Real-time PCR results of $M M P 2$ and $M M P 9$ expression, reported in Figure 7, showed a downregulation in LPS-stimulated monocytes and macrophages compared with the respective control transfected with 
the empty vector, demonstrating the involvement of the lncRNA in the regulation of gene expression of the two MMPs.

A

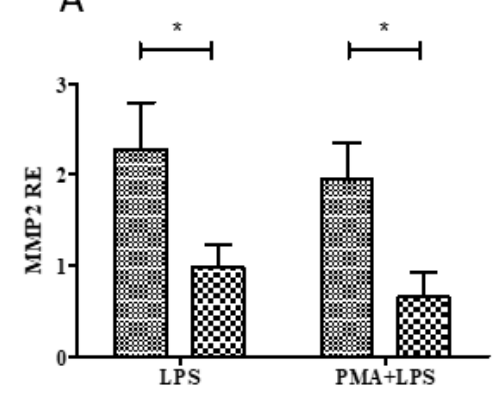

B

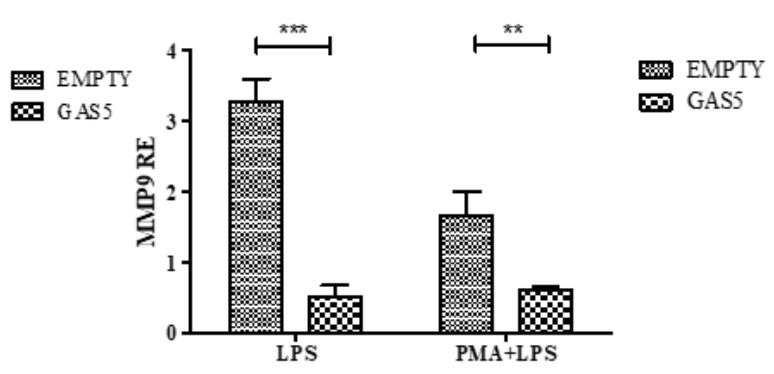

Figure 7. Levels of MMP2 (A) and MMP9 (B) after overexpression of GAS5 (GAS5) in monocyte stimulated with LPS (LPS) and macrophages stimulated with LPS (PMA + LPS) and in controls (EMPTY). MMP2 and MMP9 expression were normalized using GAPDH gene and relative expression (RE) values are expressed as $2^{-\Delta \Delta \mathrm{Ct}}$. Two-way ANOVA: EMPTY vs. GAS5 MMP2 $p=0.002$, MMP9 $p<0.0001$ Bonferroni's multiple comparison post-test ${ }^{*} p<0.05,{ }^{* *} p<0.01,{ }^{* * *} p<0.001$.

\subsection{MMP2 and MMP9 Proteins Released by THP1 Cells Overexpressing GAS5}

To confirm the role of GAS5 in regulating the expression of MMP2 and MMP9, their levels in the supernatant of both LPS-stimulated monocytes and PMA-differentiated macrophages overexpressing GAS5 were evaluated by enzyme-linked immunosorbent assay (ELISA) test. As reported in Figure 8, $M M P 9$ was less expressed in GAS5-transfected monocytes with respect to the control; no difference was detected measuring MMP2 levels. Overexpressing GAS5 significantly downregulated both MMP proteins in macrophages stimulated with LPS compared to the cells transfected with the empty vector (Figure 8).

A

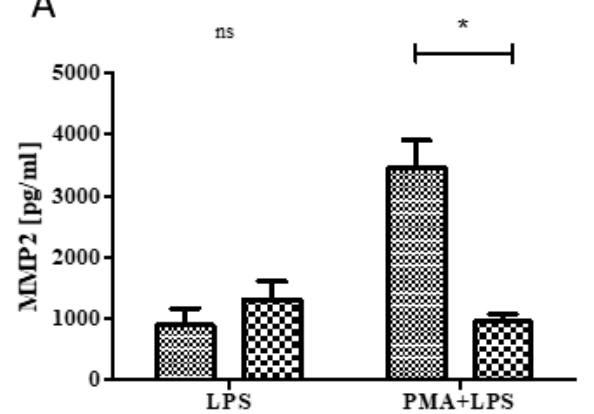

B

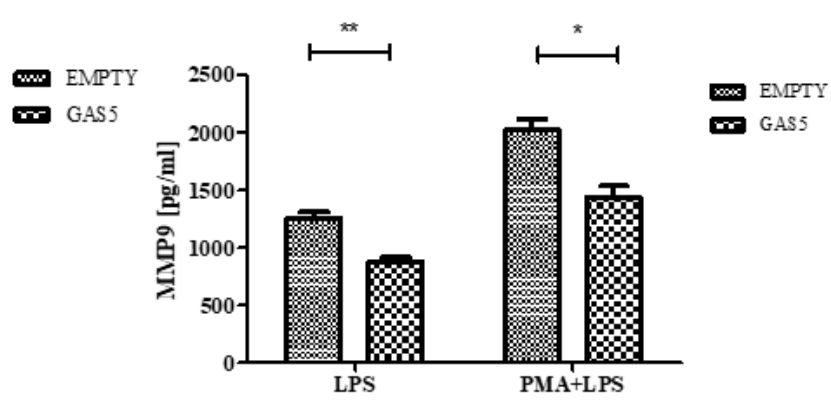

Figure 8. Evaluation of levels of MMP2 (A) and MMP9 (B) after overexpression of GAS5 (GAS5) in monocyte stimulated with LPS (LPS) and macrophages stimulated with LPS (PMA + LPS) and control (EMPTY). Two-way ANOVA: EMPTY vs. GAS5 MMP2 $p=0.02$, MMP9 $p<0.0001$ Bonferroni's multiple comparison post-test ${ }^{*} p<0.05,{ }^{* *} p<0.01 ;$ ns $=$ not significant.

\section{Discussion}

In IBD pediatric patients, genetic and environmental factors are responsible for the alteration in the epithelial barrier; the activity of pro-inflammatory elements released from macrophages, $\mathrm{T}$ cells, and innate lymphoid cells is also important [19]. MMPs have a key role in this context: In addition to playing a central role in ECM turnover, they activate or degrade a variety of other substrates including chemokines, cytokines, growth factors, and junctional proteins [20].

Several studies have shown that MMP2 and MMP9 are highly expressed in IBD inflamed colonic mucosa, serum, urine, and fecal samples [7,21-23]. However, the molecular mechanism by which the levels of these enzymes can be modulated during the inflammatory response still remains unclear. 
Recently, it has been suggested that lncRNAs may play an important role in the pathophysiology of IBD, and many researches have therefore covered this topic. Forty-seven IncRNAs dysregulated in IBD were identified, and, even though their exact role requires more studies, it has been suggested that they might have a crucial role in the regulation of inflammatory pathways [24].

The present study explores the role of the lncRNA GAS5 as a regulator of two important mediators of inflammatory response in IBD: MMP2 and the MMP9. In particular, we evaluated the expression of GAS5, MMP2, and MMP9 in biopsies of drug-naïve patients with CD and UC. Our results showed that the expression of the lncRNA in patients with IBD was lower in inflamed tissues compared to the adjacent normal part, while the expression levels of $M M P 2$ and MMP9 increased in inflamed biopsies, confirming previously published results $[3-5,22,23]$.

As reported in the literature, GAS5 seems to play a role in various inflammatory and autoimmune diseases such as rheumatoid arthritis and systemic lupus erythematosus in which significantly reduced GAS5 levels in immune cells were shown $[25,26]$. Moreover, the lncRNA is differently expressed in pediatric patients with IBD treated with glucocorticoids and positively correlates with steroid resistance, suggesting a role of GAS5 in the modulation of drug efficacy [27].

Preliminary data have already shown that GAS5 is involved in the regulation of these two MMPs, indeed Chen et al. have shown that the expression of MMP2 and MMP9 is inversely correlated with the levels of the lncRNA GAS5 in melanoma cells [15]. Overexpression of GAS5 reduced the levels of the proteins whereas the knockdown increased their expression [15].

Our work is the first report in which the potential role of GAS5 in the regulation of MMPs in IBD patients is described. Interestingly, data obtained from our cohort highlight a negative correlation between GAS5 levels and the clinical scores PUCAI (Pediatric Crohn's Disease Activity Index) and PCDAI (Pediatric Ulcerative Colitis Activity Index). These scores currently are the most rigorously developed non-invasive disease activity indexes in the field of childhood IBD, combining subjective reporting of the degree of abdominal pain, stool pattern, and general well-being and laboratory test results (hematocrit, erythrocyte sedimentation rate, and serum albumin) into a single score. PUCAI and PCDAI scores are significantly higher in patients with active disease while a score of $<10$ is consistent with inactive disease [28]. Endoscopy and clinical indexes are not always perfectly correlated because some symptoms are not related to the mucosal inflammation: GAS5 levels could be a specific molecular marker useful to better predict disease activity and stratify the severity of the disease. This result further highlights the need to investigate the potential function of GAS5 in IBD pathogenesis and progression. Currently, significant correlations between two lncRNAs quantified in the ileum of CD patients, LINC01272 and HNF4A-AS1, and more severe mucosal injury were found, but no correlation with clinical disease activities has been reported [29]. Differently, for GAS5, no correlation was found with endoscopic and inflammation scores in our cohort of patients; however, the clinical score was also not associated with these parameters in our study, as already described [30].

Considering that remodeling of the ECM and cell surface by MMPs is one of the most important function of monocytes and macrophages we decided to investigate the role of GAS5 in the regulation of MMP expression in the THP1 monocyte cell line. In particular, in vitro experiments at different stages of differentiation, from monocyte to macrophages, stimulated with a proinflammatory factor were conducted. The results confirmed the trend observed in patients for the three genes: Stimulation with LPS promotes a downregulation of GAS5 in both monocytes and macrophages, while an increase of MMPs was observed. This data highlight that, in response to immune activation, GAS5 is transcriptionally repressed but the mechanism involved needs to be further investigated.

We thus studied the effects of GAS5-overexpression on the production of MMPs in response to LPS stimulation in terms of gene and protein expression. Forced expression of GAS5 in monocytes and macrophages stimulated with LPS led to a reduction of levels of MMPs in both RNA and proteins, supporting the role of GAS5 in modulating their expression, probably at the transcriptional level. It would be interesting to evaluate in our cellular model whether the reduced expression of GAS5 could induce an increase of MMP2 and MMP9 expression as already reported in other cells [15]. 
It is well known that lncRNAs can regulate gene expression at the epigenetic, transcription, RNA processing, and translation levels [31]. The presence of GAS5 both in the cytoplasm and the nucleus was confirmed in our previous study [27]. Functional studies have demonstrated that GAS5 suppresses transcription by recruiting the histone methyltransferase polycomb repressive complex 2 to the promoter region of target genes, inhibiting gene expression [32]; further interaction studies by means of chromatin immunoprecipitation should be focused on this pathway to demonstrate the molecular mechanism by which GAS5 regulates MMPs transcription.

Moreover, GAS5 seems to have a protective role during the induction of inflammation: Its upregulation repressed the MMPs, acting as an anti-inflammatory agent. Actually, only one paper describing GAS5 expression after LPS-induced inflammation was published. The authors found that GAS5 was downregulated in ATDC5 chondrocyte cells and its overexpression alleviated LPS-induced injury [33]. Moreover, the expression levels of tumor necrosis factor (TNF)- $\alpha$, interleukin (IL)-1 $\beta$, IL-6, and IL-8 were all significantly lowered by GAS5 overexpression. The mechanism proposed by the authors is that GAS5 could modulate LPS-induced inflammatory damage through regulation of Krüppel-like factor 2 expression and inhibition of the nuclear factor kappa-light-chain-enhancer of activated B cells (NF-kB) pathway [33].

In conclusion, the present study provides new information about the functional role of GAS5 in IBD patients: The lncRNA seems to be regulated by pro-inflammatory factors and could have an important role in mediating tissue damage by modulating the expression of MMP2 and MMP9. In the future, the functional role of intestinal epithelium should be also investigated in this context using an innovative platform such as intestinal organoids.

Moreover, this study provides new perspectives to stratify IBD phenotype by using as a single measurement GAS5 expression in biopsies and supplies novel targets for future drug development in IBD.

\section{Materials and Methods}

\subsection{Clinical Samples and Histologic Evaluation}

Twenty-five IBD pediatric patients were enrolled at diagnosis at the gastroenterology department of the Pediatric Clinic of IRCCS Burlo Garofolo in Trieste. For each patient, during colonoscopy, two biopsies of the endoscopically inflamed and non-inflamed areas were collected. TRIzol ${ }^{\circledR}$ reagent was used for RNA isolation. Protein analysis was also performed on inflamed and non-inflamed biopsies obtained from three additional patients and immediately frozen on dry ice.

Histologic evaluation was performed for all patients enrolled in the study in which an adequate sampling was obtained according to European Crohn's and Colitis Organisation (ECCO) guidelines (two biopsies for the five segments of the colon and terminal ileum) [34]. Histologic activity was described using a predefined histologic inflammatory score and an architectural abnormalities score, developed for a previous study [35].

Both inflammatory and architectural score were described with a range from 0 (absence of inflammatory activity) to 5 (maximal inflammatory activity) calculated considering three defined morphological elements:

- active inflammation (neutrophils aggressive toward the glandular structures in the lamina propria) (range from 0 to 3 );

- $\quad$ crypt abscesses (range from 0 to 1 );

- $\quad$ erosions and ulcerations (i.e., presence of granulation tissue) (range from 0 to 1 ).

Architectural abnormalities comprised three defined characteristics:

- glandular crypts alteration (range from 0 to 3);

- basal plasmacytosis (range from 0 to 1 );

- epithelioid granulomas (range from 0 to 1 ). 


\subsection{Ethical Considerations}

Local ethical committee approval for the study (Protocol number: 2198; 17th September 2013) was provided. The study was conducted in accordance with the principles outlined in the Declaration of Helsinki, and the parents of all the participating children gave written informed consent before the study began. Inclusion criteria were pediatric patients (5-18 years) with a diagnosis of CD or UC. Exclusions criteria were: a) patients already treated with immunosuppressive drugs at the diagnosis; b) disease requiring immediate surgical intervention; c) severe ulcerative colitis or toxic megacolon; d) any of the following conditions: active infection; stool culture positive for enteric pathogens; tumors; human immunodeficiency virus; transplanted organ; or non-controlled disease of the kidney, liver, endocrine system, heart, blood, nervous system, or brain.

\subsection{Total RNA Isolation}

Total RNA was extracted from biopsies and cells using TRIzol reagent (Thermo Scientific, Carlsbad, CA, USA) according to manufacturer's instructions. The RNA concentration and purity were calculated by Nano Drop instrument (NanoDrop 2000, EuroClone, Milan, Italy).

\subsection{Quantitative Real-Time PCR}

Expression levels of GAS5, MMP2, and MMP9 genes were evaluated by real-time RT-PCR TaqMan ${ }^{\circledR}$ analysis using the CFX96 real-time system-C1000 Thermal Cycler (Bio-Rad Laboratories, Hercules, CA, USA). The reverse transcription reaction was carried out with the High Capacity RNA-to-cDNA Kit (Applied Biosystem, Foster City, CA, USA) and the real-time PCR was performed in triplicate using the TaqMan ${ }^{\circledR}$ Gene Expression Assay to assess GAS5, MMP2, and MMP9 mRNA expressions, according to the manufacturer's instructions. The thermal cycling conditions for TaqMan assays were as follows: $2 \mathrm{~min}$ at $50^{\circ} \mathrm{C}$ and $10 \mathrm{~min}$ at $95^{\circ} \mathrm{C}$ followed by 40 cycles at $95^{\circ} \mathrm{C}$ for $15 \mathrm{~s}$ and $60^{\circ} \mathrm{C}$ for $60 \mathrm{~s}$.

The expression levels of GAS5, MMP2, and MMP9 were evaluated using the comparative $\mathrm{Ct}$ method ( $2^{-\triangle \Delta C t}$ method). The GAS5, MMP2, and MMP9 expression values were normalized using the RPLP0 gene for studies encompassing tissues sampled from IBD patients [36] and the 18S or GAPDH genes for the in vitro studies.

\subsection{Immunoblotting}

Inflamed and non-inflamed biopsies, obtained from the colon of IBD patients, were frozen, homogenized and then lysed using a lysis buffer composed of Tris-HCl $10 \mathrm{mM} \mathrm{pH} \mathrm{7.4,} \mathrm{EDTA} 100 \mathrm{mM}$, $\mathrm{NaCl} 100 \mathrm{mM}$, SDS 0.1\%, and protease inhibitor cocktail 1\% (Sigma, Saint Louis, MO, USA). The protein concentration was determined using the Bradford reagent (Sigma, Saint Louis, MO, USA). Samples were run in a denaturing $10 \%$ polyacrylamide gel (Thermo Fisher Scientific, Carlsbad, CA, USA) and were transferred to a PVDF membrane (Thermo Fisher Scientific, Carlsbad, CA, USA) that was incubated overnight at $4{ }^{\circ} \mathrm{C}$ with primary antibodies (anti-actin 1:10000 (42 kDa), anti-MMP9 1:1000 (92 kDa), and anti-MMP2 1:1000 (74 kDa); Sigma Saint Louis, MO, USA). The secondary antibodies were an anti-mouse horseradish peroxidase (HRP) conjugated secondary antibody (Cell Signaling, Danvers, MA, USA), diluted 1:40000 and an anti-rabbit HRP-conjugated secondary antibody (OriGene, Herford, Germany) diluted 1:1000. The reaction was developed with a chemiluminescence reagent containing luminol (Euroclone, Milan, Italy). Chemiluminescence was developed using LiteAblot ${ }^{\circledR}$ TURBO (Euroclone, Milan, Italy) and exposed on Kodak Biomax film. MMP protein expression was quantified using the ImageJ software, version $1.45 \mathrm{~s}$ and was reported as percentage with respect to actin.

\subsection{Cell Line and Stimulation}

The THP1 human monocytic cell line (ATCC, TIB-202) was grown in RPMI 1640 medium (Sigma-Aldrich, Saint Louis, MO, USA) supplemented with 10\% fetal bovine serum 1\% L-glutamine $200 \mathrm{mM}, 1 \%$ penicillin 10,000 UI/mL, and streptomycin $10 \mathrm{mg} / \mathrm{mL}$. The cell cultures were maintained 
according to standard procedures in a humidified incubator at $37^{\circ} \mathrm{C}$ with $5 \% \mathrm{CO}_{2}$, and cell passage was performed twice a week. THP1 cells were differentiated into macrophages using $5 \mathrm{ng} / \mathrm{mL}$ of phorbol-12-myristate 13-acetate (PMA, Sigma-Aldrich, Saint Louis, MO, USA) for two days. Monocytes (THP1) and macrophages (THP1 + PMA) were stimulated with lipopolysaccharide (LPS; Sigma, Saint Louis, MO, USA) $1 \mu \mathrm{g} / \mathrm{mL}$ for $3 \mathrm{~h}$.

\subsection{Transient Transfection}

The full-length of GAS5 sequence was sub-cloned into pcDNA3.1 plasmid to generate pcDNA3.1-GAS5. The empty pcDNA3.1 plasmid was used as negative control. Shortly before transfection, $5 \times 10^{5}$ cells were seeded in twenty-four-well plates in $500 \mu \mathrm{L}$ of complete medium. A total of $1 \mu \mathrm{g}$ of DNA was diluted in $3 \mu \mathrm{L}$ of TransIT ${ }^{\circledR}$-Jurkat transfection reagent (Mirus Bio, Madison, USA) and, after $10 \mathrm{~min}$ of incubation, the complexes were added dropwise onto the cells according to the manufacturer's protocol. Twenty-four hours after transfection, cells were incubated with fresh RPMI medium and then stimulated as described above. The analysis of GAS5 overexpression was carried out after $24 \mathrm{~h}$ using real-time RT-PCR.

\subsection{MMP2 and MMP9 Quantification}

Cell culture supernatant obtained from THP1 cells, transfected with pcDNA3.1-GAS5 and then exposed to LPS, PMA, and PMA + LPS as described above, was analyzed using Human MMP2 and MMP9 ELISA Kit (Sigma-Aldrich, Saint Louis, MO, USA), according to the manufacturer's instructions.

\subsection{Statistical Analyses}

Statistical analyses were performed using GraphPad Prism version 4.00. Since the distribution of gene expression data in tissues obtained from patients was not parametric, data were normalized by logarithmic transformation and paired t-test was applied. One-way ANOVA or two-way ANOVA with Bonferroni post-test and $t$ test were used for the in vitro studies of gene and protein expression; $p$-values $<0.05$ were considered statistically significant.

Supplementary Materials: Supplementary materials can be found at http://www.mdpi.com/1422-0067/20/21/ 5280/s1.

Author Contributions: Conceptualization, M.L.; data curation, M.L., L.P., M.B., A.D.S., A.M., S.M., V.V., S.D.I., and G.S.; formal analysis, M.L., G.D., and G.S.; funding acquisition, S.D.I. and G.D.; methodology, M.L., L.P., M.B., D.C., A.D.S., A.M., A.B. (Alberta Bergamo), V.V., A.B. (Anna Bozzola), and M.C.; resources, (Alberta Bergamo); supervision, M.L., G.D., and G.S.; writing—original draft, M.L., L.P., and D.C.; writing-review and editing, M.B., S.M., V.V., S.D.I., G.D., and G.S.

Funding: This study was supported by the Italian Ministry of Health (no. 44/GR-2010-2300447).

Conflicts of Interest: The authors declare no conflict of interest.

$\begin{array}{ll}\text { Abbreviations } \\ \text { lncRNA } & \text { Long non-coding RNA } \\ \text { GAS5 } & \text { Growth arrest-specific transcript } 5 \\ \text { MMPs } & \text { Matrix metalloproteinases } \\ \text { IBD } & \text { Inflammatory bowel disease } \\ \text { CD } & \text { Crohn's disease } \\ \text { UC } & \text { Ulcerative colitis } \\ \text { LPS } & \text { Lipopolysaccharide } \\ \text { PMA } & \text { Phorbol-12-myristate 13-acetate } \\ \text { ECM } & \text { Extracellular matrix components } \\ \text { PCDAI } & \text { Pediatric Crohn's Disease Activity Index } \\ \text { PUCAI } & \text { Pediatric Ulcerative Colitis Activity Index }\end{array}$




\section{References}

1. Kim, D.H.; Cheon, J.H. Pathogenesis of inflammatory bowel disease and recent advances in biologic therapies. Immune Netw. 2017, 17, 25-40. [CrossRef] [PubMed]

2. Petrey, A.C.; Motte, C.A. The extracellular matrix in IBD: A dynamic mediator of inflammation. Curr. Opin. Gastroenterol. 2017, 33, 234-238. [CrossRef] [PubMed]

3. Lakatos, G.; Hritz, I.; Varga, M.Z.; Juhász, M.; Miheller, P.; Cierny, G.; Tulassay, Z.; Herszényi, L. The impact of matrix metalloproteinases and their tissue inhibitors in inflammatory bowel diseases. Dig. Dis. 2012, 30, 289-295. [CrossRef] [PubMed]

4. Garg, P.; Vijay-Kumar, M.; Wang, L.; Gewirtz, A.T.; Merlin, D.; Sitaraman, S.V. Matrix metalloproteinase-9-mediated tissue injury overrides the protective effect of matrix metalloproteinase-2 during colitis. Am. J. Physiol. Gastrointest. Liver. Physiol. 2009, 296, G175-G184. [CrossRef] [PubMed]

5. Stallmach, A.; Chan, C.C.; Ecker, K.W.; Feifel, G.; Herbst, H.; Schuppan, D.; Zeitz, M. Comparable expression of matrix metalloproteinases 1 and 2 in pouchitis and ulcerative colitis. Gut 2000,47,415-422. [CrossRef] [PubMed]

6. Matusiewicz, M.; Neubauer, K.; Mierzchala-Pasierb, M.; Gamian, A.; Krzystek-Korpacka, M. Matrix metalloproteinase-9: Its interplay with angiogenic factors in inflammatory bowel diseases. Dis. Markers 2014, 2014, 643645. [CrossRef]

7. Bailey, C.J.; Hembry, R.M.; Alexander, A.; Irving, M.H.; Grant, M.E.; Shuttleworth, C.A. Distribution of the matrix metalloproteinases stromelysin, gelatinases A and B, and collagenase in Crohn's disease and normal intestine. J. Clin. Pathol. 1994, 47, 113-116. [CrossRef]

8. Meijer, M.J.; Mieremet-Ooms, M.A.; van der Zon, A.M.; van Duijn, W.; van Hogezand, R.A.; Sier, C.F.; Hommes, D.W.; Lamers, C.B.; Verspaget, H.W. Increased mucosal matrix metalloproteinase-1, $-2,-3$ and -9 activity in patients with inflammatory bowel disease and the relation with Crohn's disease phenotype. Dig. Liver. Dis. 2007, 39, 733-739. [CrossRef]

9. Lucafò, M.; Stankovic, B.; Kotur, N.; Di Silvestre, A.; Martelossi, S.; Ventura, A.; Zukic, B.; Pavlovic, S.; Decorti, G. Pharmacotranscriptomic biomarkers in glucocorticoid treatment of pediatric inflammatory bowel disease. Curr. Med. Chem. 2018, 25, 2855-2871. [CrossRef]

10. Xu, D.; Jiang, Y.; Yang, L.; Hou, X.; Wang, J.; Gu, W.; Wang, X.; Liu, L.; Zhang, J.; Lu, H. Long noncoding RNAs expression profile and functional networks in rheumatoid arthritis. Oncotarget 2017, 8, 95280-95292. [CrossRef]

11. Wu, G.C.; Pan, H.F.; Leng, R.X.; Wang, D.G.; Li, X.P.; Li, X.M.; Ye, D.Q. Emerging role of long noncoding RNAs in autoimmune diseases. Autoimmun Rev. 2015, 14, 798-805. [CrossRef] [PubMed]

12. Ye, J.; Wang, C.; Wang, D.; Yuan, H. LncRBA GSA5, up-regulated by ox-LDL, aggravates inflammatory response and MMP expression in THP-1 macrophages by acting like a sponge for miR-221. Exp. Cell Res. 2018, 369, 348-355. [CrossRef] [PubMed]

13. Keenan, C.R.; Schuliga, M.J.; Stewart, A.G. Pro-inflammatory mediators increase levels of the noncoding RNA GAS5 in airway smooth muscle and epithelial cells. Can. J. Physiol. Pharmacol. 2015, 93, 203-206. [CrossRef]

14. Ito, I.; Asai, A.; Suzuki, S.; Kobayashi, M.; Suzuki, F. M2b macrophage polarization accompanied with reduction of long noncoding RNA GAS5. Biochem. Biophys. Res. Commun. 2017, 493, 170-175. [CrossRef] [PubMed]

15. Chen, L.; Yang, H.; Xiao, Y.; Tang, X.; Li, Y.; Han, Q.; Fu, J.; Yang, Y.; Zhu, Y. LncRNA GAS5 is a critical regulator of metastasis phenotype of melanoma cells and inhibits tumor growth in vivo. Oncol. Targets Ther. 2016, 9, 4075-4087. [CrossRef]

16. Chen, L.; Yang, H.; Xiao, Y.; Tang, X.; Li, Y.; Han, Q.; Fu, J.; Yang, Y.; Zhu, Y. Lentiviral-mediated overexpression of long non-coding RNA GAS5 reduces invasion by mediating MMP2 expression and activity in human melanoma cells. Int. J. Oncol. 2016, 48, 1509-1518. [CrossRef]

17. Koelink, P.J.; Overbeek, S.A.; Braber, S.; Morgan, M.E.; Henricks, P.A.; Abdul Roda, M.; Verspaget, H.W.; Wolfkamp, S.C.; te Velde, A.A.; Jones, C.W.; et al. Collagen degradation and neutrophilic infiltration: A vicious circle in inflammatory bowel disease. Gut 2014, 63, 578-587. [CrossRef]

18. Kim, C.S.; Kang, J.H.; Cho, H.R.; Blankenship, T.N.; Erickson, K.L.; Kawada, T.; Yu, R. Potential involvement of CCL23 in atherosclerotic lesion formation/progression by the enhancement of chemotaxis, adhesion molecule expression, and MMP-2 release from monocytes. Inflamm Res. 2011, 60, 889-895. [CrossRef] 
19. Silva, F.A.; Rodrigues, B.L.; Ayrizono, M.L.; Leal, R.F. The immunological basis of inflammatory bowel disease. Gastroenterol. Res. Pract. 2016, 2016, 2097274. [CrossRef]

20. Van Lint, P.; Libert, C. Chemokine and cytokine processing by matrix metalloproteinases and its effect on leukocyte migration and inflammation. J. Leukoc. Biol. 2007, 82, 1375-1381. [CrossRef]

21. Buisson, A.; Vazeille, E.; Minet-Quinard, R.; Goutte, M.; Bouvier, D.; Goutorbe, F.; Pereira, B.; Barnich, N.; Bommelaer, G. Fecal matrix metalloprotease- 9 and lipocalin-2 as biomarkers in detecting endoscopic activity in patients with inflammatory bowel diseases. J. Clin. Gastroenterol. 2018, 52, e53-e62. [CrossRef] [PubMed]

22. Manfredi, M.A.; Zurakowski, D.; Rufo, P.A.; Walker, T.R.; Fox, V.L.; Moses, M.A. Increased incidence of urinary matrix metalloproteinases as predictors of disease in pediatric patients with inflammatory bowel disease. Inflamm. Bowel Dis. 2008, 14, 1091-1096. [CrossRef] [PubMed]

23. Kofla-Dłubacz, A.; Matusiewicz, M.; Krzesiek, E.; Noga, L.; Iwańczak, B. Metalloproteinase-3 and -9 as novel markers in the evaluation of ulcerative colitis activity in children. Adv. Clin. Exp. Med. 2014, 23, 103-110. [CrossRef] [PubMed]

24. Yarani, R.; Mirza, A.H.; Kaur, S.; Pociot, F. The emerging role of lncRNAs in inflammatory bowel disease. Exp. Mol. Med. 2018, 50, 161. [CrossRef]

25. Mayama, T.; Marr, A.K.; Kino, T. Differential expression of glucocorticoid receptor noncoding RNA repressor Gas5 in autoimmune and inflammatory diseases. Horm. Metab. Res. 2016, 48, 550-557. [CrossRef]

26. Wu, G.C.; Hu, Y.; Guan, S.Y.; Ye, D.Q.; Pan, H.F. Differential plasma expression profiles of long non-Coding RNAs reveal potential biomarkers for systemic lupus erythematosus. Biomolecules 2019, 9, 206. [CrossRef]

27. Lucafò, M.; Di Silvestre, A.; Romano, M.; Avian, A.; Antonelli, R.; Martelossi, S.; Naviglio, S.; Tommasini, A.; Stocco, G.; Ventura, A.; et al. Role of the long non-coding RNA growth arrest-specific 5 in Glucocorticoid response in children with inflammatory bowel disease. Basic. Clin. Pharmacol. Toxicol. 2018, 122, 87-93. [CrossRef]

28. Turner, D.; Otley, A.R.; Mack, D.; Hyams, J.; de Bruijne, J.; Uusoue, K.; Walters, T.D.; Zachos, M.; Mamula, P.; Beaton, D.E.; et al. Development, validation, and evaluation of a pediatric ulcerative colitis activity index: A prospective multicenter study. Gastroenterology 2007, 133, 423-432. [CrossRef]

29. Haberman, Y.; BenShoshan, M.; Di Segni, A.; Dexheimer, P.J.; Braun, T.; Weiss, B.; Walters, T.D.; Baldassano, R.N.; Noe, J.D.; Markowitz, J.; et al. Long ncRNA Landscape in the ileum of treatment-naive early-onset crohn disease. Inflamm. Bowel. Dis. 2018, 24, 346-360. [CrossRef]

30. Carman, N.; Tomalty, D.; Church, P.C.; Mack, D.R.; Benchimol, E.I.; Otley, A.R.; Jacobson, K.; Huynh, H.Q.; DeBruyn, J.C.; El-Matary, W.; et al. Clinical disease activity and endoscopic severity correlate poorly in children newly diagnosed with Crohn's disease. Gastrointest. Endosc. 2019, 89, 364-372. [CrossRef]

31. Angrand, P.O.; Vennin, C.; Le Bourhis, X.; Adriaenssens, E. The role of long non-coding RNAs in genome formatting and expression. Front. Genet. 2015, 6, 165. [CrossRef] [PubMed]

32. Sun, D.; Yu, Z.; Fang, X.; Liu, M.; Pu, Y.; Shao, Q.; Wang, D.; Zhao, X.; Huang, A.; Xiang, Z.; et al. LncRNA GAS5 inhibits microglial M2 polarization and exacerbates demyelination. EMBO Rep. 2017, 18, 1801-1816. [CrossRef] [PubMed]

33. Li, F.; Sun, J.; Huang, S.; Su, G.; Pi, G. LncRNA GAS5 overexpression reverses LPS-induced inflammatory injury and apoptosis through up-regulating KLF2 expression in ATDC5 chondrocytes. Cell Physiol. Biochem. 2018, 45, 1241-1251. [CrossRef] [PubMed]

34. Magro, F.; Langner, C.; Driessen, A.; Ensari, A.; Geboes, K.; Mantzaris, G.J.; Villanacci, V.; Becheanu, G.; Nunes, P.B.; Cathomas, G.; et al. European consensus on the histopathology of inflammatory bowel disease. J. Crohns Colitis. 2013, 7, 827-851. [CrossRef] [PubMed]

35. Lazzerini, M.; Villanacci, V.; Pellegrin, M.C.; Martelossi, S.; Magazzù, G.; Pellegrino, S.; Lucanto, M.C.; Barabino, A.; Calvi, A.; Arrigo, S.; et al. Endoscopic and Histologic Healing in Children With Inflammatory Bowel Diseases Treated With Thalidomide. Clin Gastroenterol. Hepatol. 2017, 15, 1382-1389. [CrossRef]

36. Krzystek-Korpacka, M.; Diakowska, D.; Bania, J.; Gamian, A. Expression stability of common housekeeping genes is differently affected by bowel inflammation and cancer: Implications for finding suitable normalizers for inflammatory bowel disease studies. Inflamm. Bowel. Dis. 2014, 20, 1147-1156. [CrossRef]

(C) 2019 by the authors. Licensee MDPI, Basel, Switzerland. This article is an open access article distributed under the terms and conditions of the Creative Commons Attribution (CC BY) license (http://creativecommons.org/licenses/by/4.0/). 